\title{
Reducing hours of work of preregistration house officers: report on a shift system
}

\author{
D G Nasmyth, A Pickersgill, $M$ Hogarth
}

\begin{abstract}
Objective-To determine the advantages and disadvantages of a shift system of working compared with the conventional on call system for preregistration house officers.

Design-A shift system of working was employed in the unit from 1 August 1989 to $31 \mathrm{July} 1990$. During attachments of three or six months four house officers rotated at intervals of one month among three daytime shifts and one night shift (Mondays to Fridays only). Weekends (48 hours) were worked on a one in three rota by the doctors working a day shift. The views of the house officers working this shift system were sought in writing and by direct interview.

Setting-Professorial surgical unit, Royal Liverpool Hospital.
\end{abstract}

Subjects-The 14 house officers who were attached to the unit for three or six months during their preregistration year.

Results - The shift system was preferred to conventional on call without exception. The incidence over between shifts resulted in more informed decision making by doctors while on call. During annual leave it was sometimes necessary to revert to the conventional one in three on call system to ensure that daytime work was completed. Other disadvantages were the long weekend shift and an inequitable distribution of the night shift. The house officers recommended extending the shifts to weekends and working the night shift one week in four.

Conclusion-A shift system of working was effective in reducing chronic tiredness among house officers, who found it preferable to conventional on call arrangements. Shift working is feasible only if the daytime duties of the doctor working at night can be completed by the other doctors on the rota.

\section{Introduction}

In an attempt to solve the problem of prolonged continuous working for house officers we introduced a shift system in the professorial surgical unit at the Royal Liverpool Hospital for the preregistration year 1 August 1989 to 31 July 1990.

Royal Liverpool Hospital, Liverpool L7 8XP

D G Nasmyth, FRCS, senior registrar

A Pickersgill, $\mathrm{MB}$, house

officer

Maxine Hogarth, MB, house officer

Correspondence to:

Mr D G Nasmyth,

Department of Surgery,

Walton Hospital, Liverpool

L9 1AE.

BMF 1991;302:93-4 a registrar, two senior house officers, and four preregistration house officers. One house officer is attached to the unit for six months. The remaining three house officers work in the unit for three months, rotating for the other three months of their preregistration surgical appointment to the departments of orthopaedics, urology, or vascular surgery. The unit has the use of 36 beds, including four high dependency beds. of chronic tiredness was reduced and formal hand-

Additional beds are available in a five day ward and a day unit. The unit accepts emergency general surgical admissions on two weekdays and every third weekend and patients with haemorrhage from oesophageal varices at any time. The house officers work a one in four on call rota with prospective cover for absent colleagues; they do not cross cover other units within the hospital. There is always a more senior member of the unit's non-consultant staff on call.

Subjects-Twelve house officers (nine men, three women) were attached to the unit for three months and two house officers (one man, one woman) for the whole six months of their preregistration surgical appointments. All of the house officers had worked a conventional on call system at the hospital.

Shift system-During the day shift from 8 am to 630 pm (101/2 hours) on Monday to Friday two house officers each worked for a single consultant, and the third house officer worked for two consultants. The fourth house officer worked the night shift from $6 \mathrm{pm}$ to $830 \mathrm{am}$ (141/2 hours) on Monday to Friday. The three house officers who worked the day shift each worked a weekend shift from 8 am on Saturday until 8 am on Monday ( 48 hours) one weekend in three. The weekend shift was continuous with the day shift on a Monday, thus creating a maximum period of continuous working of $581 / 2$ hours. The doctors working a day shift and one in three weekends worked an average of $681 / 2$ hours each week and those on the night shift $72 \frac{1}{2}$ hours each week. The shifts changed on the first day of each calendar month, so that no house officer worked more than one month on the night shift. The house officers on the day shift worked for a different consultant or pair of consultants each month. All the house officers met at the beginning of each shift $(6 \mathrm{pm}$ and $8 \mathrm{am}$ ) for a formal handover. Annual leave was taken only when house officers were working the day shift. Whenever possible help with the duties of the doctor on leave was provided by a final year medical student. Alternatively, the shift system was put into abeyance and the three remaining doctors worked a conventional one in three on call rota.

Evaluation of the shift system - During the final three months of the preregistration year a letter was sent to each of the house officers, who were invited to comment on the shift system compared with conventional on call arrangements. The shift system was subsequently discussed with each of the 14 house officers individually by one of us (DGN). The shift system was also discussed informally with the consultants and their views obtained. hospitalis - The professorial surgical unit at our

\section{Results}

Without exception the shift system of working was preferred to the conventional on call rotas. The doctors on the night shift usually worked continually until about $2 \mathrm{am}$. Between $2 \mathrm{am}$ and $7 \mathrm{am}$ the workload was 


\begin{tabular}{|c|c|c|c|c|c|c|c|c|c|c|c|c|c|}
\hline & \multicolumn{13}{|c|}{ Week No } \\
\hline & 1 & 2 & 3 & 4 & 5 & 6 & 7 & 8 & 9 & 10 & 11 & 12 & 13 \\
\hline & \multicolumn{13}{|c|}{ Monday to Friday 8 am to $630 \mathrm{pm}$} \\
\hline Consultant W & A & A & $\mathrm{C}$ & $\mathrm{C}$ & $\mathrm{C}$ & D & D & $\mathrm{D}$ & B & B & B & A & A \\
\hline Consultant X & B & $\mathrm{B}$ & B & A & A & $\mathrm{A}$ & $\mathrm{C}$ & $\mathrm{C}$ & $\mathrm{C}$ & $\mathrm{D}$ & $\mathrm{D}$ & D & B \\
\hline \multirow[t]{3}{*}{ Consultants $\mathrm{Y}$ and $\mathrm{Z}$} & C & $\mathrm{D}$ & $\mathrm{D}$ & $\mathrm{D}$ & $\mathrm{B}$ & $\underset{\text { arday }}{\mathrm{B}}$ & $\underset{\text { riday }}{\mathrm{B}}$ & $\begin{array}{r}\mathrm{A} \\
\text { n to }\end{array}$ & $\underset{a m}{\mathrm{~A}}$ & A & $\mathrm{C}$ & $\mathrm{C}$ & $\mathrm{C}$ \\
\hline & $\mathrm{D}$ & $\mathrm{C}$ & A & B & $\mathrm{D}_{S}$ & \multicolumn{3}{|c|}{ Saturday and Sunday 8 am to $630 \mathrm{pm}$} & $\underset{p m}{\mathrm{D}}$ & $\mathrm{C}$ & A & B & $\mathrm{D}$ \\
\hline & A & $\mathrm{B}$ & D & $\mathrm{C}$ & $\mathrm{A}$ & B & $\mathrm{D}$ & $\mathrm{C}$ & A & B & $\mathrm{D}$ & $\mathrm{C}$ & A \\
\hline
\end{tabular}

variable, but the opportunity for sleep was rare. Most doctors slept between 9 am and $2 \mathrm{pm}$ and used the period from $2 \mathrm{pm}$ to $6 \mathrm{pm}$ for recreation.

Advantages of the shift system-The shift system guaranteed the opportunity for a period of undisturbed sleep in each 24 hours between Monday and Friday, resulting in a reduction in chronic tiredness, increased efficiency of daytime working, and a lessening of the frustration associated with repetitive tasks (for example, phlebotomy). Obligatory handover between shifts facilitated easier and better management decisions by the doctor on the night shift. Because there was no backlog of daytime work the doctors devoted more time to the management of acute problems and had more time to avail themselves of teaching on emergency cases by senior staff. Working for a different consultant each month increased the breadth of experience and permitted more informed decision making while on call, as did the familiarity with clinical problems that resulted from working five consecutive nights. A weekend on call was perceived as less stressful as there were no on call duties in the preceding or following weeks.

Disadvantages of the shift system-The shift system described was inequitable: most house officers worked in the unit for three months, and as there were four of them at any one time some did not work the night shift at all. Secondly, the weekend shift, which was continuous with the Monday day shift, was too onerous, lasting $581 / 2$ hours. Finally, the daytime workload was uneven, which meant that during annual leave the shift system had to be abandoned on occasions because at certain times in the week two doctors could not cope with the peaks of daytime work, although at other times there was insufficient work to occupy three doctors on the day shift until $6 \mathrm{pm}$.

Recommendations of house officers - The house officers thought that the shift system should be continued but modified so that the maximum period of continuous working is $14 \frac{1}{2}$ hours. Each doctor should work the night shift for seven consecutive nights in every 28 days. Each doctor should also work a day shift on Saturdays and Sundays one weekend in four (table). The daytime workload of house officers, which is uneven, should be reviewed. Appropriate revision of the weekly timetable might obviate the need to revert to a conventional one in three on call rota during periods of annual leave.

Consultants' evaluation of shift system-From the consultants' viewpoint the principal consequence of the shift system was a new house officer each month and less time in which the consultant and the house officer could get to know each other. Because the consultants in the unit have tended to integrate their practices and most policies are those of the unit rather than those of four individual consultants this was not seen as a major problem. The consultants' perception of the shift system in other respects reflected that of the house officers; they were particularly anxious that the formal handover between shifts was continued.

\section{Discussion}

The shift system employed in this first trial year was inadequate in two major respects: the distribution of the night shift among the house officers was inequitable, and the doctor on call at the weekend worked for $581 / 2$ hours. A long weekend shift had been retained because working split weekends (dividing the 48 hours between 8 am Saturday and 8 am Monday between at least two doctors) has never been popular. The solution to these inadequacies proposed by the house officers themselves would, however, entail them working for a part of one in two weekends as opposed to the whole of one in three or one in four weekends. It is testimony to the misery of working for long periods without sleep that this solution should come from them.

Despite the apparent success of the shift system in this unit it would be premature to recommend it as a universal remedy for reducing periods of continuous working for house officers or, indeed, for other junior staff. A shift system is probably not viable with fewer than four doctors on a rota because working for part of two weekends in three is unlikely to be acceptable to the doctors concerned, and for two doctors to do the daytime work of three is a proportionately greater increase than three doctors doing the work of four. If prospective cover is applied to a rota of four doctors working a shift system the daytime work must be done by two doctors. In this unit two house officers were not always able to do the daytime work of their absent colleagues, and the shift system was put into abeyance to enable three doctors to work during the day. It should be pointed out that this was in a unit that is relatively generously staffed, and there was no dependence on house officers to attend clinics or operating lists, factors that must be weighed in considering the application of a shift system to other grades of junior staff. This problem of inadequate staffing to meet the daytime workload has led to the option of a shift system being rejected previously.'

Despite the reservations it would be surprising if the circumstances prevalent in this unit that made shift working both possible and successful were unique. The results of this experiment with a shift system of working for preregistration house officers suggest that it is a pattern of working that they prefer, it is of benefit to the service, and there is no evidence from its use in this unit that there is any detriment to the house officers educationally. In the light of this experience the current house officers in the unit are working the modified shift system proposed by their predecessors.

We thank the consultant staff of the unit, Professor Sir Robert Shields, Mr S J Leinster, Mr A N Kingsnorth, and Mr B A Taylor; the clinical subdean, Dr A Carty; and all the house officers for their continued encouragement and support.

1 Leslie PJ, Williams AJ, McKenna C, Smith G, Heading RC. Hours, volume, and type of work of preregistration house officers. $B M \mathcal{J}$ 1990;300: 1038-41. 